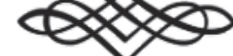

The physiological dimension of being-in-the-world.

An inquiry into the Heideggerian understanding of corporeality

\title{
La dimensión fisiológica del ser-en-el-mundo. Una indagación en la comprensión beideggeriana de la corporalidad
}

\author{
Hernán Javier Candiloro \\ (CONICET - UBA) \\ DOI: http://dx.doi.org/10.15366/bp2018.18.004 \\ Bajo Palabra. II Época. No18. Pgs: 77-98
}


Recibido: 30/01/2017

Aprobado: 29/07/2018

\section{Resumen}

Se ha criticado a Heidegger por su supuesto "olvido del cuerpo". Sin embargo, a partir de una lectura atenta es posible rastrear una comprensión del cuerpo que, aunque implícita, es prácticamente omnipresente en su pensamiento. Se trata, pues, de una corporalidad que determina de manera originaria al ser-enel-mundo -el cuerpo viviente- y no ya de un cuerpo físico, ente intramundano concebido antropológicamente. En este contexto, el presente artículo se propone reconstruir la comprensión heideggeriana de la corporalidad y demostrar su importancia en el marco de la analítica existenciaria.

Palabras clave: cuerpo, mundo, sentimiento, organismo, prótesis, hambre.

\section{Abstract}

Heidegger has been criticized for his supposed "forgetting of the body". However, from an attentive reading it is possible to trace an understanding of the body that, although implicit, is practically omnipresent in his thought. It is, therefore, a corporeality that determines originally the being-in-the-world -the living body- and not a physical body, an intramundane entity conceived anthropologically. In this context, the present article aims to reconstruct the Heideggerian understanding of corporeality and demonstrate its importance within the framework of existential analytic.

Keywords: body, world, feeling, organism, prosthesis, hunger. 
Para Jess

$y$ el lorito.

\section{Introducción}

Es COMÚN SEŃALAR LA AUSENCIA de una investigación temática sobre la corporalidad en la obra de Heidegger. Sin embargo, existen distintas menciones y referencias que hacen posible la -por cierto necesaria- reconstrucción de su comprensión ${ }^{1}$. Desde la amanualidad [Zuhandenheit] que signa el trato con los útiles -recordemos al pasar que "tratar con" algo se dice en alemán "be-handeln"-, pasando por el "espaciamiento" [Ent-fernung] y el "encontrarse" [Befindlichkeit]; Ser y tiempo parece implícitamente exigirnos la postulación de un cuerpo que resulta constantemente elidido en la analítica existenciaria ${ }^{2}$.

¿Qué pasa entonces con el cuerpo en el pensamiento de Heidegger? ¿Acaso el pensador que se ha destacado por denunciar el "olvido del ser" ha incurrido él mismo en un "olvido del cuerpo"? ¿Y no sería este olvido del cuerpo, al igual que aquel otro del ser, una característica de la historia de la metafísica? ¿No ha sido ésta la que, en efecto, ha rebajado incesantemente la corporalidad -res extensa- como gesto correlativo y necesario para el entronizamiento de la razón -res cogitans-? ¿Pero no es sin embargo ese cuerpo -el de la metafísica, el cuerpo que puede ser señalado como "ese" (tóde ti)- el que, por estar determinado de antemano como ente intramundano y no ser entonces fenomenológicamente originario, Ser y tiempo se resiste a tratar temáticamente? ${ }^{3}$.

\footnotetext{
${ }^{1}$ Sobre la crítica a Heidegger, así como sobre la respuesta de éste cf. Askay, R. R., "Heidegger, the body and the french philosophers", Continental Philosophy Review, N 32, Holanda, Kluwer, 1999, pp. 29-35.

2 Todas las citas de Heidegger siguen la edición alemana de las obras completas Gesamtausgabe [de aquí en adelante citado como GA], Frankfurt am Main, Klostermann, 1976-2016. En todos los casos donde no se indique traductor la traducción es mía. Cf. Heidegger, M., GA 2, p. 145: "El espaciamiento del Dasein en su "corporalidad», que guarda en sí una problemática propia que aquí no trataremos [...]".

${ }^{3}$ Como señala Luisa Paz Rodríguez Suárez, Ser y tiempo pone en cuestión la determinación antropológica de la corporalidad, para abrir la pregunta por su dimensión ontológica. Cf. Rodríguez Suárez, L. P., "Heidegger y el fenómeno del cuerpo. Apuntes para una antropología postmetafísica", Thémata. Revista de filosofía, № 46, 2012 (segundo semestre), pp. 209-216, especialmente p. 212: "[...] la corporalidad será entendida, pues, como una dimensión ontológica -no antropológica, si por tal se entiende la antropología tradicional-”. Sobre los motivos de la ausencia del cuerpo en Ser y tiempo cf. Escudero, J. A., "Heidegger y el olvido del cuerpo", Lectora, № 17 , pp. 182-183.
} 
¿Cuál sería entonces un adecuado abordaje del cuerpo? ¿Hay, pues, una comprensión de la corporalidad implícita en el análisis del ser-en-el-mundo? ${ }^{4}$ ¿No es acaso la corporalidad la forma primera y más básica de exterioridad y exposición extática, esto es, de existencia [Existenz] mundana? ¿Qué puede significar la exposición al mundo si no el hecho de tener que ser corporal para existir? Y por otra parte, ¿qué trato puede tener el Dasein con los útiles o de qué modo puede "procurar por" [fürsorgen] los otros - "extenderles una mano", para decirlo con un tópico caro a Heidegger ${ }^{5}$ - sino teniendo que "poner el cuerpo"?

¿En qué consiste ese ente cuya proximidad más próxima que cualquier cercanía lo hace pasar cotidianamente desapercibido? ¿De qué modo y en qué circunstancia ese cuerpo presupuesto, implícito e incluso constantemente elidido tras el trato con los entes sale de su obviedad para mostrarse tal cual es? ¿Cuáles son, pues, las condiciones para una explicitación originaria del cuerpo?

\section{La piel del ser-en-el-mundo}

Considerado en sentido propio, el cuerpo no es un ente más de cuyo trato el Dasein se ocupe transitivamente ${ }^{6}$ como medio para un fin. El cuerpo no es un ente más, puesto que lo vivo en cada caso como "mío" 7 . No es por lo general la meta de la ocupación sino, por el contrario, su sujeto y su agente. No nos ocupamos de nuestro cuerpo como de un ente cualquiera, sino que más bien nos ocupamos de los entes con el cuerpo. Sin embargo, aunque este no sea la meta de la ocupación, tampoco representa un simple medio para ella. El cuerpo acompaña y agencia el trato con los entes, y para que este sea posible es menester que el ente esté ya dispuesto en relación a nuestro cuerpo, presentándose en ciertas condiciones de cercanía y manipulabilidad adecuadas a las determinaciones corporales ${ }^{8}$.

Algo es visto a cierta distancia de un ojo, oído en una cierta frecuencia que se corresponde con un oído, tocado cuando se encuentra inmediatamente junto a la piel. Incluso lo imaginado o soñado es imaginado y sońado por la singularidad de un

\footnotetext{
${ }^{4}$ Así como la crítica sartreana enfatiza la importancia del cuerpo como primer punto de contacto que el ser humano establece con el mundo, en su respuesta Heidegger apunta que "el tratamiento del fenómeno del cuerpo viviente no es en absoluto posible sin una elaboración suficiente de los rasgos fundamentales del existenciario ser-en-el-mundo". Heidegger, M., GA 89, p. 202.

5 Cf. Derrida, J., "La main de Heidegger”, Psyché. Inventions de l'autre, París, Galilée, 1987.

${ }^{6}$ El prefijo "be" de be-sorgt refiere a este carácter transitivo de la ocupación con los entes, aunque, como veremos más adelante, dicha transitividad no excluya una remisión al Dasein que vincula a la besorgen con la voz media.

7 Cf. Heidegger, M., GA 89, p. 113.

${ }^{8}$ Fue Husserl quien postuló al cuerpo propio como punto cero de toda orientación. Cf. Husserl, E., Ideas II, trad. A. Zirión Q., México, FCE, 2005, pp. 88-89.
} 
cuerpo. El mundo y los entes que en él aparecen se corresponden con un horizonte signado por nuestras posibilidades corporales. El zapato lleva la forma, la medida, la huella de un pie que puede portarlo, así como la forma y las dimensiones del vaso del que nos servimos se corresponden con las de una mano que puede tomarlo y de una boca que puede beber de él. El color de un árbol remite a la capacidad de visión de un determinado ojo, la bocina de una alarma a la peculiar capacidad auditiva de un oído al que aturde. "El mundo" no es objetivo ni neutral, sino que en su descripción yacen implícitas referencias a los órganos y capacidades de quien lo habita, las marcas corporales -las "huellas digitales"- del Dasein".

Con la producción en serie estas referencias a la corporalidad tienden sin embargo a estandarizarse, prefigurando una comprensión del cuerpo "normal" ${ }^{10}$. Ya no es entonces el ente el que es dispuesto de acuerdo a la corporalidad en cada caso singular, sino que ahora es ésta la que debe esforzarse para adecuarse a un mundo en el que ha sido normativizada de antemano. La estandarización del ente configura así un cuerpo normal al que es necesario ajustarse y con el que se debe negociar constantemente. Ya no es el zapato el que es hecho a la medida del pie, sino que es ahora el pie el que debe adaptarse a la horma estándar del zapato para poder calzar. La silla ya no se adapta a la anatomía de un cuerpo, sino que es ahora el cuerpo el que se rige por las dimensiones estándar de la silla, producida industrialmente en serie de acuerdo a criterios de eficacia y rentabilidad ${ }^{11}$.

Los entes nos hacen lugar, se abren hospitalariamente para que podamos tratar con ellos. Entendida a partir de la amanualidad, esta hospitalidad apunta al cuerpo del Dasein. Los entes tienen la forma de la mano del Dasein, pero no sólo ni siempre de la mano física -ese órgano prensil que consta de una palma rodeada de cinco dedos- sino ante todo y en primer lugar de lo que Heidegger denomina la mano -en singular- y que hace referencia a ese vínculo corporal primario con las cosas. Los entes nos hacen un lugar, son hospitalarios con nosotros y es en ese espacio

\footnotetext{
9 De allí que el impresionismo busque plasmar la impresión que, en el instante correcto, la luz y el color causan en el artista, esa hora en la que, por ejemplo, los tallos de las plantas son violeta. "En nosotros, escribe René Huygue, la vida ha hecho indisolubles la sensación y la idea que de ella nos hacemos, al punto que la perfecta exactitud sensorial se torna de hecho una inexactitud humana. En su obsesión de llegar a un absoluto de la sensación Cézanne ha salido de la zona reconocida, familiar, hasta el punto que la multitud acusa de error a su ojo, cuyo único defecto es el de ceder a una lucidez demasiado rigurosa”. Citado en H. Perruchot, Vida de Cézanne, trad. H. A. Maniglia, Buenos Aires, Hachette, 1955, p. 260. “El cielo es azul, ¿no le parece?, y eso, fue Monet quien lo encontró... Monet no es más que un ojo, pero, ¡buen Dios!, ¡qué ojo!”. Ibid. p. 279

${ }^{10}$ Cf. Heidegger, M., GA 2, pp. 70-71: "La obra producida remite no sólo al para-qué de su empleabilidad y al de-qué de su constitución. En las situaciones artesanales más sencillas yace en aquella al mismo tiempo la referencia al portador y utilizador. La obra es cortada a la medida de su cuerpo [jLeib y no Körper! nota del Autor]; él mismo "está» en el surgimiento de la obra. En la producción por docena no falta en absoluto esta referencia constitutiva; sólo que ella está indeterminada, apunta al cualquiera, el promedio”.

11 Esto puede verse con claridad, por ejemplo, en la estrechez y disposición de los asientos en los medios de transporte.
} 
donde, tendiendo nuestra mano, nos tendemos nosotros mismos para vincularnos con ellos ${ }^{12}$.

El cuerpo no ocupa el centro de nuestra atención y cuando lo hace aparece apenas como cuerpo físico [Körper], organismo intramundano, pero nunca como cuerpo viviente $\left[\right.$ Leib ${ }^{13}$. ¿Se da entonces alguna instancia en la que podamos experimentar propiamente nuestro cuerpo en tanto que cuerpo viviente, y no ya como mero cuerpo físico?

Pero así como, considerado aisladamente, el Dasein es apenas un elemento formal, una abstracción del fenómeno más originario, complejo y concreto del ser-enel-mundo, es en este último donde deberemos rastrear esa experiencia originaria del cuerpo viviente. Éste debe ser pensado, por ende, como la dimensión fisiológica inherente al ser-en-el-mundo, y no como el cuerpo ónticamente determinado de un sujeto aislado -el cuerpo físico- en cuyo desvelamiento el cuerpo viviente se encuentra ya oculto y presupuesto. Es necesario entonces repensar la corporalidad en su dimensión ontológica-existenciaria [existenzial] y no ya meramente óntica-existente [existenziell]. Es menester, en suma, indagar en la corporalidad como el aspecto carnal, la piel, del ser-en-el-mundo.

\section{El sentimiento o el ser-en-el-mundo encarnado}

Considerado ontológicamente, el Cuerpo no tiene lugar junto a otros entes, ni puede tampoco ser considerado un ente intramundano, no está determinado sustancialmente, ni su contorno puede ser delimitable en el espacio. El cuerpo viviente carece en general de extensión. Sus límites se superponen y coinciden con los del ser-en-el-mundo: "Corporalizar [Leiben] forma siempre parte del ser-en-el-mundo. Codetermina siempre el ser-en-el-mundo, el estar-abierto, el tener de mundo" 14 . Mientras que los límites del cuerpo físico están determinados espacialmente, los del cuerpo viviente coinciden con el mundo. Y de la misma manera en que el análisis fenomenológico no puede traspasar los límites del ser-en-el-mundo para mostrarlo

\footnotetext{
12 "La mano del hombre: sin duda lo han notado, Heidegger no piensa solamente la mano como una cosa muy singular, y que pertenecería propiamente sólo al hombre. La piensa siempre en singular, como si el hombre no tuviera dos manos sino, esta monstrensca, una sola mano. No un sólo órgano en el medio del cuerpo, como el cíclope tenía un sólo ojo en el medio de la frente, aunque esta representación, que deja mucho que desear, da también mucho que pensar. No, la mano del hombre, esto significa que no se trata ya de estos órganos prensiles o de estos miembros instrumentalizables que son las manos". Derrida, J., "La main de Heidegger", op. cit., p. 438.

13 Cf. Heidegger, M., GA 6.1, p. 96: "El estado corporal viviente [Leibzustand] de un animal e incluso del hombre es algo esencialmente distinto a la composición de un cuerpo físico [Körper], por ejemplo, de una piedra. Todo cuerpo viviente es también un cuerpo físico, pero no todo cuerpo físico es "cuerpo viviente» [Leib]".

14 Heidegger, M., GA 89, p. 126.
} 
como una totalidad completamente determinada, tampoco es posible salirse del propio cuerpo para seńalarlo desde fuera. La imposibilidad no es sólo fáctica, sino por sobre todo ontológica: el cuerpo acompaña al mundo donde quiera que vaya y se encuentra presupuesto en todo señalamiento. El cuerpo viviente es esencialmente mundano, tanto como el mundo es intrínsecamente corporal ${ }^{15}$. Así pues, la única delimitación posible de ambos fenómenos deberá provenir de su interior.

Heidegger se detiene en la cuestión del cuerpo en el marco de su tratamiento de la "fisiología del arte" en los cursos sobre Nietzsche. El planteo allí tiene lugar en torno al sentimiento [Gefühl], mientras que para el análisis de este último Heidegger apela a uno de los conceptos centrales de Ser y tiempo: las tonalidades afectivas [Stimmungen]. Tanto el sentimiento como la tonalidad afectiva se caracterizan por abrir, de manera originaria y simultáneamente, el modo en el que nos encontramos ante nosotros mismos y ante las cosas que aparecen en el mundo ${ }^{16}$. Las tonalidades afectivas y los sentimientos se encuentran así a la base de la diferencia entre la mismidad y el resto de los entes, a la vez que los abren simultáneamente sobre su trasfondo común. Tan originales como el ser-en-el-mundo, sentimientos y tonalidades envuelven y determinan al ente en su totalidad ${ }^{17}$. Esta simultaneidad de la apertura del sí-mismo y del resto de los entes señala -aquí como en otros textos de Heidegger ${ }^{18}$ - la copertenencia entre ambos polos: el ser-en-el-mundo, entendido como diferencia originaria y originante de la distinción.

Heidegger oscila continuamente entre las tonalidades y los sentimientos. Los sentimientos no son meros estados de ánimo que acontezcan en la mente de un sujeto previamente determinado, sino que encarnan la dimensión corporal de la tonalidad afectiva. Ellos son el modo concreto en el que la afectividad del ser-en-

15 Cf. Zimmerman, M. E., Eclipse of the self Ohio, Ohio University Press, 1986, p. 27: "Some criticts claim that Heidegger ignores the phenomenon of the human body, but, in fact, he presupposes that bodily experience is as "wordly» as my seeing a bird on a fence. Experiences which are normally regarded as «inner» or «subjective» are entirely wordly; they are part of $m y$ wordly experience. Even my experience of myself as a conscious subject is a wordly experience. [...] Dasein is embodied opennes to what is. A felling is manifest to me just as much as is a friend. Although a feeling is different from a friend, both are manifest insofar as there is some temporal opennes in which that manifesting can occur. A gnawing pain manifests itself in my stomach; as I open the refrigerator door, a turkey leg manifests itself. Seeing the turkey leg is not more «objective» than feeling the pain in my stomach. Of course, a turkey leg is not like a pain in any ontical way, but ontologically both turkey leg and pain are revealed through me" [la cursiva es de Zimmerman].

16 Cf. Heidegger, M., GA 6.1, p. 99.

${ }^{17}$ Incluso en tonalidades como el miedo, en la que es un ente intramundano el que me asusta, es el ente en su totalidad el que es abierto en la tonalidad. "El temer como posibilidad durmiente del ser-en-el-mundo encontrándose [befindlichen In-der-Welt-sein], el «ser temeroso", ha abierto ya el mundo de modo tal que pueda acercarse a partir suyo algo así como lo temible. [...] Este "ser temeroso" no tiene que ser entendido en el sentido óntico de una fáctica tendencia "ocasional", sino como posibilidad existenciaria [existenzial] del esencial encontrarse del Dasein en general, que sin duda no es la única”. Heidegger, M., GA 2, pp. 187-189 [la cursiva es mía. Autor].

${ }_{18}$ Por ejemplo la expresión “»in eins mit«" que Heidegger utiliza en GA 9, p. 113 y ss. puede ser leída en el mismo sentido. 
el-mundo se realiza en cada caso fácticamente y son, por tanto, trascendentales respecto del ente intramundano. Los sentimientos son la condición corporal de posibilidad de toda determinación mundana y no su resultado.

El sentimiento es primordialmente un sentir los entes sintiéndose, y al mismo tiempo, un sentirse en el trato con los entes. Considerada en sentido amplio, su estructura a la vez reflexiva y transitiva equivale en cierta manera a la de la voz media. En el origen de esa partición yace la experiencia primordial del cuerpo en tanto que umbral y límite que al mismo tiempo reúne y disgrega al Dasein y al mundo. En su doble referencia a los entes y al sí-mismo, el sentimiento incluye de antemano a la corporalidad, y representa la encarnación fisiológica del ser-en ${ }^{19}$.

Así pues, si por una parte el sentimiento incluye una experiencia del cuerpo viviente, por otra contiene también una referencia igualmente insoslayable a los otros entes y, en particular, a los otros Dasein.

A la esencia de este ser le pertenece el sentimiento en tanto que sentirse. El sentimiento produce de antemano la continente inclusión del cuerpo en nuestro Dasein. Pero puesto que al sentimiento como sentirse es igualmente originario el tener en cada caso el sentimiento por el ente en su totalidad, entonces en todos los estados corporales resuena en cada caso un modo en el que nos dirigimos o no a las cosas en torno a nosotros, y a los hombres con nosotros. Un "desajuste" ["Verstimmung"] estomacal puede tender un velo de sombra sobre todas las cosas. Lo que en otro caso nos parece indiferente, es repentinamente irritante y molesto. Lo que en otro caso transcurre fácilmente, se paraliza. La voluntad puede ponerse en el medio, puede reprimir el desajuste, pero no puede despertar y crear inmediatamente la tonalidad afectiva opuesta: las tonalidades afectivas solamente vuelven a ser superadas y transformadas por tonalidades afectivas. Aquí resulta esencial prestar atención: el sentimiento no es lo que ocurre en el "interior", sino que es aquel modo fundamental de nuestro Dasein, en virtud del cual y de acuerdo con el cual estamos ya siempre levantados por sobre nosotros hacia el ente en su totalidad, que nos concierne en tal o cual manera ${ }^{20}$.

El sentimiento involucra, pues, tanto el sentirse corporalmente a sí mismo, como el simultáneo sentir los entes que se presentan en el mundo. Aquel se yergue entre nosotros mismos y el resto de los entes, diferenciando pero a la vez también remitiéndonos uno hacia el otro, poniéndonos en contacto y exponiéndonos recíprocamente. El sentimiento no es, por tanto, ni meramente subjetivo, ni tampoco una pura percepción objetiva del ente que aparece en el mundo -un "estado psico-

\footnotetext{
19 Cf. Heidegger, M., GA 2, $\$ \$ 12-13$.

20 Heidegger, M., GA 6.1, p. 99 [la cursiva es mía. Autor].
} 
lógico"-, sino que constituye una instancia simultánea que trasciende ambos polos indicando el origen de su diferenciación. Al igual que sucede con la caricia, el sentimiento contiene simultáneamente la sensación de lo acariciado y de la propia mano que acaricia. En el sentimiento se reúnen y diferencian, se confunden y a la vez se distinguen el que siente y lo sentido: "Cuando tomo el vaso, entonces siento el vaso y mi mano. Ésta es la así llamada doble sensación, es decir, la sensación de lo tocado y el sentir de mi mano". ${ }^{21}$

Pero el sentimiento no sólo hace patente la yuxtaposición corporal entre la sensación de los entes que aparecen en el mundo y el sentirse de la mismidad, sino que al mismo tiempo nos muestra que el cuerpo no es algo que se le adjunte posteriormente al Dasein. Por el contrario, el sentimiento indica la determinación recíproca originaria entre la mismidad y la corporalidad viviente. El Dasein es originariamente corporal, de la misma manera en la que, correlativamente, al cuerpo viviente le corresponde siempre un sentimiento que abarca el íntegro seren-el-mundo.

¿Dónde queda lo fisiológico, lo que tiene estado corporal [das Leibzuständliche]? Al final no debemos separarlos como si en el piso de abajo malviviera un estado corporal y en el de arriba el sentimiento. En tanto que sentirse, el sentimiento es precisamente el modo en el que somos corporales [leiblich]: ser corporal no significa que a un alma le sea todavía acoplado un armatoste llamado cuerpo [Leib], sino que en el sentirse ya está de antemano incluido el cuerpo en nuestro sí-mismo, y eso de modo tal que en sus estados nos atraviesa a nosotros mismos. No "tenemos" un cuerpo [Leib], así como llevamos un cuchillo en el bolsillo; el cuerpo viviente [Leib] tampoco es un cuerpo físico [Körper] que nos acompañe y que también consideremos, expresamente o no, en tanto que subsistente. No "tenemos" un cuerpo viviente $\left[\right.$ Leib], sino que "somos" corporales [leiblich ${ }^{22}$.

El Dasein es corporal, su modo de ser -la existencia- se caracteriza por la corporalidad. Ser-en-el-mundo significa estar encarnado en un cuerpo viviente que se hace manifiesto en el sentimiento. La tristeza que aparece con las lágrimas o el enrojecimiento vergonzoso no son, ciertamente, simples fenómenos somáticos, pero tampoco meras vivencias psíquicas. Las lágrimas son desde un primer momento materia espiritualizada. Lo determinante en ellas, el sentimiento de tristeza, no puede ser medido en la cantidad de líquido que cae de los ojos, así como la vergüenza tampoco puede ser calculada según al grado de coloración de la piel. Las manifestaciones de los sentimientos, así también como los gestos corporales -no las

\footnotetext{
${ }^{21}$ Heidegger, M., GA 89, p. 108. Sobre la caricia como contacto impersonal que trasciende lo sensible cf. Lévinas, E., Totalité et infini. Essaie sur l'extériorité, París, Kluwer, 2000, pp. 288 y ss.

22 Heidegger, M., GA 6.1, p. 99.
} 
meras posiciones del cuerpo ${ }^{23}$ - no son simples modificaciones accidentales de un cuerpo físico, que se produzcan como resultado mecánico de un estímulo aplicado sobre una materialidad indiferente, sino que reflejan un padecimiento que afecta al ser-en-el-mundo en su totalidad. Ellas son propiamente manifestaciones de un cuerpo que padece y vive el darse de un mundo ${ }^{24}$.

La tonalidad afectiva no es nunca el puro estar templado para sí en un interior, sino que es en primer lugar un determinarse [sich Be-stimmen] y dejarse templar [Stimmenlassen] en la tonalidad afectiva. La tonalidad afectiva es, pues, el modo fundamental en el que estamos fuera de nosotros mismos. Pero así somos esencial y permanentemente. [...] No somos primero "vivientes" y tenemos después además un aparato llamado cuerpo, sino que vivimos en el hecho de corporalizarnos [wir leben, indem wir leiben]. Este corporalizar es algo esencialmente diferente que el estar aquejado por un organismo ${ }^{25}$.

Como puede verse, Heidegger oscila continuamente entre el sentimiento y las tonalidades afectivas. Y ello porque si el cuerpo viviente se manifiesta primariamente en el sentimiento, este último tiene su raíz en la dimensión afectiva del ser-enel-mundo: las tonalidades. Heidegger concluye entonces que "todo sentimiento es un corporalizar templado [gestimmtes Leiben] de tal o cual manera, una tonalidad afectiva corporalizante [leibende Stimmung] de tal o cual manera" ${ }^{26}$. El sentimiento es, destacamos, una tonalidad afectiva corporalizada, esto es, una tonalidad afectiva hecha carne. El cuerpo no es primero un ente sustancial disponible que luego resulte "espiritualizado", sino que la corporalidad viviente se encuentra desde un principio entramada en la tonalidad afectiva y el ser-en-el-mundo.

\section{La mundanidad del órgano}

EL DESCUBRIMIENTO PRIMARIO DEL MUNDO radica en las tonalidades afectivas ${ }^{27}$. Éstas constituyen la condición de posibilidad de toda afección y se encuentran, por

\footnotetext{
23 "Analicemos el ejemplo de alguien que se pasa la mano por la frente en el transcurso de una de mis conferencias. En este caso no observo un cambio de lugar y posición de la mano, sino que inmediatamente comprendo que está pensando en algo complicado. [...] El cuerpo visible dispone de una especial elocuencia, en virtud de la cual un gesto presenciado tiene un carácter de solicitación, de pregunta que suscita una respuesta”. Escudero, J. A., "Heidegger y el olvido del cuerpo", op. cit., p. 187-188.

${ }^{24}$ Cf. Heidegger, M., GA 89, pp. 106-107.

${ }_{25}$ Heidegger, M., GA 6.1, p. 100 [la cursiva es de Heidegger].

26 Ídem.

27 Cf. Heidegger, M., GA 2, pp. 137-138: "En el encontrarse yace existenciariamente una referencialidad abriente al mundo, a partir de la cual puede hacer frente lo que afecta. Por principio ontológico debemos en efecto dejar el primario descubrimiento del mundo a la "mera tonalidad afectiva»" [la cursiva es siempre de Heidegger].
} 
lo tanto, a la base de la sensibilidad con la que el Dasein percibe el mundo que lo rodea. Los órganos sensoriales no son, por ende, meras herramientas para la captación de datos. Una máquina, por ejemplo, bien puede captar la misma información que un ojo -o incluso puede captar más y mejor información que éste-, sin tener, empero, propiamente la capacidad de $v^{28}{ }^{28}$. Ningún mundo yace en el lente de la cámara o en la memoria de un ordenador por fuera de que el Dasein se lo apropie. Y ello porque la percepción sólo es tal sobre la posibilidad de ser-en-el-mundo, abierta primariamente por las tonalidades afectivas ${ }^{29}$. Una máquina puede, en suma, recibir información, pero no puede ser-en-el-mundo. A diferencia de ella, los órganos en los que se articula el cuerpo biológico no constituyen meros instrumentos. Una mano no es simplemente un órgano de prensión, sino que lo que hace mano en ella arraiga en la posibilidad de ser-en-el-mundo ${ }^{30}$.

Así pues, lo que distingue al órgano de la herramienta es el hecho de estar ya siempre templado en una determinada tonalidad afectiva que le abre de antemano el ser-en-el-mundo en su totalidad, permitiéndole propiamente dirigirse hacia lo que lo rodea. El órgano se funda así en la posibilidad de ser-en-el-mundo y no a la inversa: este último no es, en ningún caso, el resultado de la recolección de datos, sino que por el contrario, representa el horizonte dentro del cual es posible toda percepción. Lo que hace ojo en el ojo, su capacidad de ver, proviene del ser-enel-mundo, siendo ontológicamente anterior al mero órgano. Es la visión la que antecede al ojo y le permite ver.

¿Es el ver producido por el ojo? Para poder decidir sobre el carácter de herramienta del ojo, debemos preguntar con mayor claridad: ¿El animal puede ver porque tiene ojos, o tiene ojos porque puede ver? ¿Por qué motivo tiene ojos el animal? ¿Por qué puede tener tales? Sólo porque puede ver. Tener ojos y poder ver no son lo mismo. El poder ver posibilita primero la posesión de ojos, la hace necesaria en una manera determinada. ¿Pero hasta qué punto y en función de qué puede ver el animal? ¿Donde reside la posibilitación de esta posibilidad, de este poder? ¿Qué tipo de posibilidad es en general ésta - el poder ver? ¿Qué carácter tiene esta posibilidad?

${ }^{28}$ Cf. Heidegger, M., GA 79, p. 37: "Incluso lo que llamamos una parte maquínica no es nunca, pensado estrictamente, una parte. Bien es verdad que está ensamblado en el mecanismo, pero como pieza intercambiable. Por el contrario mi mano no es ninguna pieza mía. Yo mismo estoy enteramente en cada gesto de la mano de una sola vez".

${ }^{29}$ Cf. Heidegger, M., GA 2, p. 183: "Y sólo porque los «sentidos" pertenecen a un ente que tiene la forma de ser del ser-en-el-mundo encontrándose, pueden ser "tocados» $\mathrm{y}$ "tener sentido para», de modo tal que lo que toca se muestre en la afección".

30 Cf. Derrida, J., "La main de Heidegger", op. cit., p. 428: "Ella [la mano] pertenece más bien a la esencia del don, de una donación que donaría, de ser posible, sin tomar nada. Si la mano es también, nadie lo puede negar, un órgano de prensión (Greiforgan), no está allí su esencia, no es la esencia de la mano en el ser humano” [la cursiva es de Derrida]. 
Preguntándolo de manera fundamental: ¿cómo tiene que ser un ente, para que esta posibilidad del poder ver tenga que poder pertenecer a su modo de ser?

El poder ver es una posibilidad esencial del animal. De ello no se sigue que todo animal deba fácticamente tener ojos, sino que sólo se dice: el poder ver como posibilidad se funda como tal en la animalidad. Sin embargo, la animalidad no tiene por qué desplegarse necesariamente hacia esta posibilidad determinada y dejar surgir ojos en el animal. Pero en su modo de ser en general ella debe ser de tal modo que le pertenezcan posibilidades como el poder ver, oír, oler, tocar. ${ }^{31}$

Las posibilidades de percepción no sólo son anteriores a los órganos sino que además son esenciales y están fundadas en el ser de la animalidad. El modo de ser de la animalidad se caracteriza, pues, por el hecho de que le pertenecen capacidades de percepción, o lo que es lo mismo, por encontrarse entramado en el ser-en-elmundo como posibilidad básica de lo viviente. Es esta posibilidad ontológica de apertura del mundo la que, con independencia de si se materializa o no en órganos, y con independencia del modo en el que lo haga -en tal o cual órgano, con tales o cuales características concretas-, determina a lo viviente en tanto tal. Las capacidades de percepción anteceden a los órganos, pudiendo incluso muchas veces transferirse entre ellos -como sucede por alguna discapacidad- o incluso encarnarse artificialmente a través de una prótesis. Es posible ver aun sin ojos, utilizando las manos o un bastón, incluso oliendo.

\section{La construcción técnica del cuerpo}

Así COMO LA AMANUALIDAD NO INHIERE exclusivamente en la mano, y entonces podemos tomar un pincel con la boca o con el pie si lo necesitamos, dicha capacidad puede también ser desplegada técnicamente mediante el uso de una prótesis. Esta última no es un objeto intramundano como cualquier otro, a través del cual el Dasein perciba lo que lo rodea sino que, por el contrario -y como se desprende de los análisis realizados por Merleau-Ponty- el Dasein percibe en ella, adoptándola como parte de su cuerpo viviente y anclándola en sus capacidades propias. Una vez que la prótesis se ha vuelto familiar, pierde su carácter intramundano para alcanzar el estrato ontológico del ser-en-el-mundo, convirtiéndose así en un apéndice del cuerpo viviente.

El bastón del ciego ha dejado de ser un objeto para él, ya no se percibe por sí mismo, su extremidad se ha transformado en zona sensible, aumenta la amplitud y

${ }^{31}$ Heidegger, M., GA $29 / 30$, pp. 319-320 [la cursiva es siempre de Heidegger]. 
el radio de acción del tocar, ha devenido análogo a una mirada. En la exploración de los objetos, la longitud del bastón no interviene expresamente y como término medio: el ciego la conoce por la posición de los objetos, más que la posición de los objetos por ella [...] Habituarse a un sombrero, a un auto o a un bastón, es instalarse en ellos, o inversamente, hacerlos participar en la voluminosidad del cuerpo propio. El hábito expresa el poder que tenemos de dilatar nuestro ser en el mundo, o de cambiar de existencia anexándonos nuevos instrumentos. ${ }^{32}$

La prótesis no es, pues, un simple objeto que se encuentre adherido al cuerpo, sino que constituye más bien un injerto que lo constituye como tal. La técnica no sólo normativiza el cuerpo a través de la producción en serie a la que éste debe adaptarse, sino que también interviene directamente sobre lo viviente, sea ampliando el alcance y la capacidad de sus órganos, ocupando directamente su lugar y

32 Merleau-Ponty, M., Phénoménologie de la perception, París, Gallimard, 1945, pp. 167-168. Cf. Ibid pp. 177-178: "La exploración de los objetos con un bastón, que dábamos recién como un ejemplo de hábito motriz, es también un ejemplo de hábito perceptivo. Cuando el bastón se vuelve un instrumento familiar, el mundo de los objetos táctiles recula, no comienza más en la epidermis de la mano, sino en la punta del bastón. Estamos tentados de decir que a través de las sensaciones producidas por la presión del bastón sobre la mano, el ciego construye el bastón y sus diferentes posiciones, y que éstas, a su vez, mediatizan un objeto a la segunda potencia, el objeto externo. La percepción sería siempre una lectura de los mismos datos sensibles, ella se haría solamente cada vez más rápido, sobre signos cada vez más tenues. Pero el hábito no consiste en interpretar las presiones del bastón sobre la mano como signos de ciertas posiciones del bastón, y éstos como signos de un objeto exterior, puesto que aquél nos dispensa de hacerlo. Las presiones sobre la mano y el bastón no están ya dadas, el bastón no es más un objeto que el ciego percibiría, sino un instrumento con el cual él percibe. Es un apéndice del cuerpo, una extensión de la síntesis corporal". Cf. Heidegger, M., GA 89, pp. 112-113: "El cuerpo físico [Körper] se termina en la piel [...] El límite del cuerpo viviente [Leibgrenze], frente al límite del cuerpo físico, no difiere cuantitativa, sino cualitativamente. El cuerpo físico como cuerpo físico no puede tener en absoluto un límite tal como el del cuerpo viviente [...] $\mathrm{Al}$ apuntar con el dedo hacia la cruz en la ventana allá fuera yo no termino en la punta de mis dedos. [...] Límite del cuerpo viviente (el cuerpo viviente sólo es en la medida en que corporaliza: cuerpo viviente) es el horizonte de ser en el que me hospedo [aufhalten]. Por ende el límite de mi cuerpo viviente cambia constantemente a través de las transformaciones del alcance de mi estancia [Aufenthalt]. El límite del cuerpo físico por el contrario por lo común no cambia, a lo sumo tal vez cuando se engorda o se adelgaza. Pero la flacura tampoco es un fenómeno del cuerpo físico, sino del cuerpo viviente. Sin embargo, el cuerpo viviente que adelgaza puede volver a ser medido como cuerpo físico de acuerdo a su peso. El volumen del cuerpo físico (el viviente no tiene ningún volumen) se ha vuelto más pequeńo". Como sostiene Escudero, “[...] cuando yo me muevo, el horizonte se aleja o aproxima en función de mi movimiento y ocupación. El límite somático -esto es, el horizonte constituido por la percepción y el gesto- está cambiando constantemente en cuanto corporalizamos [leiben], en cuanto nos movemos en situaciones de la vida diaria, mientras que el límite corporal permanece siempre el mismo". Escudero, J. A., "Heidegger y el olvido del cuerpo", op. cit., p. 187. Sería necesario, sin embargo, matizar esta des-anclaje entre las modificaciones del cuerpo físico y el viviente. En efecto, cuando el Körper cambia, junto a él se modifica también, y primariamente, la relación con el espacio y el tiempo, con los entes con los que tratamos cotidianamente y se modifica, en general y sobre todo, la sensibilidad hacia lo que nos rodea. Como sostiene Heidegger, la flacura es ante todo un fenómeno del cuerpo viviente, así como lo es, por poner otro ejemplo, el embarazo.

Por otra parte, sería interesante confrontar esta duplicidad de los cuerpos desde una perspectiva política con la teoría de "los dos cuerpos del rey" de Kantorowicz. Cf. Kantorowicz, E., Los dos cuerpos del rey: un estudio de teología politica medieval, trad. S. Aikin Araluce y R. Blázquez Godoy, Madrid, Akal, 2012; algo que excede, por supuesto los límites de este trabajo. 
remplazándolos, o incluso haciendo las dos cosas al mismo tiempo ${ }^{33}$. La muerte del órgano tiene lugar allí donde la técnica ya no alcanza a sostener la encarnación de las capacidades de vivir. En la época tecnocientífica, la técnica llega a fusionarse con el cuerpo para volverlo su producto ${ }^{34}$.

Los órganos que conforman al ser vivo no son, por ende, meras herramientas para la captación de datos, sino que se fundan en la capacidad de percibir y ésta, a su vez, lo hace en el ser de lo viviente como posibilidad de ser-en-el-mundo. El ser vivo no es entonces un mero organismo, el sistema de los órganos -una comprensión técnico-mecánica de la vida cuya procedencia Heidegger sitúa en la modernidad-, ni su ser se corresponde con el de la subsistencia ${ }^{35}$. Por el contrario, la forma de ser de lo viviente se encuentra intrínseca y esencialmente determinada por una mundanidad que en cada caso se "dispersa" en órganos ${ }^{36}$. Y es justamente esta pre-

33 Esta dialéctica entre la regulación técnica de la vida y el aprovechamiento vital de la técnica puede ser leído en el marco de la relación entre tanatopolítica y biopolítica afirmativa planteada por Esposito. Cf. Esposito, Roberto y Goldenberg, Mario, "Violento estado de excepción”, en Revista Eñe [en línea], 9 de noviembre de 2011, disponible en URL: http://www.revistaenie.clarin.com/ideas/Entrevista_Roberto_Esposito_0_493150696.html [revisado el 28 de enero de 2017].

34 Agamben sitúa el límite tecnocientífico actual en la imposibilidad de transplantar el cerebro, es decir, en la imposibilidad de suplementar la muerte del órgano en el que se encarnan nuestros recuerdos y pensamientos, nuestra identidad. Cf. Agamben, G., Homo Sacer I. El poder soberano y la nuda vida, trad. A. G. Cuspinera, Valencia, Pre-Textos, 2006, p. 207: "En 1974 el abogado defensor de Andrew D. Lyons, acusado ante un tribunal californiano de haber matado a un hombre de un tiro de pistola, objetó que la causa de la muerte no había sido el proyectil lanzado por su cliente, sino la extracción de su corazón, llevada a cabo en estado de muerte cerebral, por el cirujano Norman Shumway para efectuar un transplante. El doctor Shumway no fue inculpado pero no es posible leer sin incomodidad la declaración con que convenció al tribunal de su inocencia: "Afirmo que un hombre cuyo cerebro ha muerto, está muerto. Éste es el único órgano que no puede ser transplantado" [...] En buena lógica, esto implicaría que, dado que la muerte cardíaca ha dejado de proporcionar un criterio válido con el descubrimiento de las tecnologías de reanimación y transplante, la muerte cerebral dejaría de ser tal, en consecuencia, el día en que se produjera, hipotéticamente, el primer transplante de cerebro. La muerte pasa a convertirse de esta forma en un epifenómeno de la tecnología del transplante" [la cursiva es mía. HJC]. Sobre la fusión entre vida y técnica cf. Jünger, Ernst, El trabajador, trad. A. Sánchez Pascual, Barcelona, Tusquets, 1993, pp. 165 y 173-174: "Ya en páginas anteriores tocamos de pasada el concepto de construcción orgánica; ésta se exterioriza, por lo que se refiere al tipo, como una fusión estrecha y sin contradicciones del ser humano con los instrumentos que están a su disposición"; así también como el texto fundamental acerca de la cuestión cyborg, a saber, Haraway, D., Ciencia, cyborgs y mujeres. La reinvención de la naturaleza, trad. M. Talens, Madrid, Cátedra, 1995, en especial p. 253: "Un cyborg es un organismo cibernético, un híbrido de máquina y organismo, una criatura de realidad social y también de ficción".

35 Cf. Heidegger, M., GA 9, p. 255: "[...] desde el dominio del pensar moderno lo viviente es comprendido como «organismo». Bien puede todavía durar mucho tiempo hasta que aprendamos a ver que el pensamiento del «organismo» y de lo "orgánico» es un concepto puramente moderno y mecánico-técnico, de acuerdo al cual la planta es interpretada como algo creado que se hace a sí mismo".

36 Cf. Heidegger, M., GA 26, p. 173: "El Dasein en general alberga la intrínseca posibilidad de una fáctica dispersión en la corporalidad y, así, en la sexualidad. [...] El Dasein, en cuanto fáctico, está en cada caso escindido, entre otras cosas, en un cuerpo y a la vez, por esto disociado, entre otras cosas, en un determinado sexo. [...] [La dispersión no trata de la representación de] que una esencia originaria es partida ónticamente en su simplicidad en muchos particulares, sino de la aclaración de la posibilidad interna de la multiplicidad que, como veremos todavía más precisamente, yace en todo Dasein y para la que la corporalidad representa un factor de organización". Como sostiene Escudero respecto de la supuesta "asexualidad" -o más precisamente "neutralidad" sexual- 
sencia de órganos sensoriales en el animal la que, considerada desde su fundamento en el ser-en-el-mundo, lo expone como un otro en el que podríamos eventualmente transponernos [sich versetzen]. Los órganos remiten al ser-en-el-mundo, que sólo se da disperso y corporalizado. En ello reside lo propio de la animalidad. O como sostiene con claridad Michel Haar:

Hay entonces una relación de las facultades a los órganos en la esencia de la vida: esta relación designa un campo de "propiedad" que caracteriza a cada ser viviente. El animal tiene una relación de retorno sobre sí-mismo [lui-même], se alimenta, se defiende, se reproduce; esta relación es independiente de la cuestión de la posesión o no de una conciencia de sí [soi]. Esta relación a sí no es la de la ipseidad, pero no le es absolutamente diferente ${ }^{37}$.

\section{El cuerpo tiene sus necesidades}

Así COMO NUESTROS ÓRgANOS NO SON INSTRUMENTOS, tampoco aquello de lo que vivimos -de lo que vive nuestro cuerpo- es un simple medio para la sobrevida del Dasein. Por el contrario, el Dasein vive y se vive en aquello de lo que se alimenta. Lévinas ha caracterizado con justeza esta manera de vivir peculiar al Dasein, aunque haya pretendido deslindarla del planteo de Heidegger.

Vivimos de "buena sopa", de aire, de luz, de espectáculos, de trabajo, de ideas, de sueño, etc ... Éstos no son objetos de representaciones. Vivimos de ellos. Esto de lo que vivimos, no es tampoco "medio de vida", como la pluma es medio con relación a la carta que permite escribir; ni una meta de la vida como la comunicación es meta de la carta. Las cosas de las que vivimos no son instrumentos, ni tampoco utensilios, en el sentido heideggeriano del término. Su existencia no se agota en el esquematismo utilitario que los diseña, como la existencia de martillos, agujas o máquinas. Son siempre, en cierta medida -y aun los martillos, las agujas y las máquinas lo son- objetos del gozo, que se ofrecen al "gusto", ya adornados, embellecidos. ${ }^{38}$

que Sartre le imputa al Dasein heideggeriano: "El Dasein, en cuanto apertura al mundo, no remite a los términos «mujer» $\mathrm{y}$ "hombre» y sus correspondientes atributos fisiológicos. En términos ontológicos, esta apertura es la que hace posible la corporalidad y la sexualidad. [...] Heidegger evita una discusión temática del cuerpo, pues su análisis de la vida humana se centra en las estructuras ontológicas que hacen posible cualquier experiencia significativa del cuerpo en virtud del estar-en-el-mundo. Y estas estructuras ontológicas, que también podemos denominar condiciones de posibilidad de toda vivencia corporal, son asexuales (geschlechtlos) y neutrales (neutral), porque son más originarias que las características biológicas particulares de hombre y mujer y más originarias que cualquier diferencia de género". Escudero, J. A., "Heidegger y el olvido del cuerpo", op. cit., pp. 189-190. Acerca de la neutralidad sexual del Dasein cf. Derrida, J., "Geschlecht, différence sexuelle, différence ontologique”, Haar, M. (comp.), Cahier de l'Herne consacré à Heidegger, París, L’Herne, 1983, pp. 419-430.

37 HaAr, M., Le chant de la terre. Heidegger et les assises de l'histoire de l'être, París, L'Herne, 1985, p. 65.

38 LÉvinas, E., Totalité et infini. Essaie sur l'extériorité, op. cit., pp. 112-113 [la cursiva es mía. HJC]. 
A diferencia de lo planteado por Lévinas en el fragmento precedente, el vínculo esencial de hospitalidad entre el Dasein y los entes impide llevar adelante una lectura pragmatista del trato con éstos. La Sorge se desenvuelve en un espacio anterior más originario, tanto a la distinción teórico-práctico, como a la separación entre transitividad y reflexividad ${ }^{39}$.

Los entes cuyo ser es la amanualidad no pueden ser considerados como meros útiles puestos ahí en tanto que instrumentos disponibles para servir al Dasein. Por el contrario, el ser de éste está implicado en los entes con los que trata y sólo por esa razón puede involucrarse en y con ellos. El Dasein no usa -transitivamente- los entes, sino que también simultáneamente se ocupa -en una voz media- de y con ellos: su ser está involucrado en los entes con los que trata y por eso debe ser cuidadoso y precavido ${ }^{40}$. Implicado esencialmente en aquello con lo que trata, debe preservar sus marcas -la marca de su mano en sentido amplio- para poder reconocerse. Pero ese reconocimiento y hospitalidad con lo ente son puestos en cuestión mediante la producción de artículos en serie que estandariza las referencias corporales para volver al ente pura mercancía ${ }^{41}$.

${ }^{39}$ Cf. Heidegger, M., GA 2, pp. 57: "El título ["Besorgen», ocuparse] no fue entonces elegido porque a veces el Dasein sea inmediatamente y en gran escala económico y "práctico», sino porque el ser mismo del Dasein tiene que ser hecho visible como cuidado [Sorge]". Cf. Ibid. pp. 300-301: "Pero el cuidado [Sorge], como asistencia [Fürsorge] que se ocupa [besorgende] abarca el ser del Dasein tan original y completamente, que debe ser ya presupuesta como un todo en la separación del conducirse teorético y práctico, y no puede ser recién montado a partir de estas capacidades con ayuda de una dialéctica necesariamente carente de fundamento, porque no ha sido fundada existenciariamente". Cf. también Inwood, M., A Heidegger dictionary, Oxford, Blackwell, 1999, p. 35: "The verb sorgen is «to care» in two senses: (a) sich sorgen um is "to worry, be worried about» something; (b) sorgen für is "to take care of, see to, provide (for)» someone or something [...] These three concepts [sorgen, besorgen y fürsorgen] enable Heidegger to distinguish his own view from the view that our attitude towards the world is primarily cognitive and theoretical. Descartes's and Husserl's "concern for known knowledge» (Sorge um erkante Erkenntnis) is only one type of concern, and not the primary, or a self-evidently appealing, type (GA 17, p. 62; GA 63, p. 106). But Sorge is not specifically practical: it lies deeper than the customary contrast between theory and practice (GA 2, p. 93)".

${ }^{40}$ Esta cautela en el trato se hace patente en la "circunspección" [Umsicht], entendida en sentido de "ver en torno" pero también de cuidado y precaución, que caracteriza el trato cotidiano del Dasein. Cf. la explicación a la traducción de "Umsicht" que realiza Rivera en Heidegger, M., Ser y tiempo, trad. Jorge Eduardo Rivera C., Santiago de Chile, Editorial Universitaria, 1997, p. 467. Cf. también Heidegger, M., GA 2, p. 93.

${ }^{41}$ Resulta particularmente interesante notar esta borradura de la mano en el ámbito del arte y la escritura. Cf. Warhol, A., "What is pop art? Interviews with eight painters (Part 1)", AA.VV, Art news, Noviembre, Nueva York, 1963, p. 26: "The reason I'm painting this way is that I want to be a machine, and I feel that whatever I do and do machine -like is what I want to do." En esta misma línea resulta interesante traer a colación la famosa frase de Roy Lichtenstein en su entrevista con John Coplans en 1967: "I want my painting to look as if it has been programmed. I want to hide the record of my hand". Sobre la mano en el arte, cf. Kundera, M., "Le geste brutal du peintre: sur Francis Bacon”, Une rencontre, París, Gallimard, 2009, pp. 15-30. Cf. también Derrida, J., "La main de Heidegger", op. cit., p. 427: "La meditación sobre la Hand-Werk auténtica tiene también el sentido de una protesta artesanal contra el borramiento o la degradación de la mano en la automatización industrial del maquinismo moderno. Esta estrategia tiene efectos equívocos, lo sabemos; ella abre a una reacción arcaizante hacia el artesanado rústico y denuncia el negocio o el capital cuyas nociones sabemos bien a quien estaban asociadas. Además, con la división del trabajo, es implícitamente lo que llamamos «trabajo intelectual» el que 
Por detrás de esta estandarización yace el peligro de que el Dasein se fagocite al ente al considerarlo apenas un medio para su subsistencia orgánica. Pareciera ser allí, en ese espacio vacío que las cosas abren hospitalariamente hacia el hombre, donde ha tenido lugar la detonación de la bomba atómica ontológica que nos condena al trato con meros objetos de consumo ${ }^{42}$. El pan y la buena sopa se convierten entonces en combustible, carbohidratos y proteínas a ser consumidas por un cuerpo que sólo las necesita para seguir produciendo otras mercancías, dispuestas a su vez para el aprovechamiento de otros cuerpos.

Paradójicamente, el hambre aumenta junto con la producción de alimentos. De la misma tierra de la que se extrae compulsivamente alimento, se extrae también miseria y hambruna. Como afirma Esposito: "[...] sobre el mismo territorio y al mismo tiempo, junto a bombas de alto poder destructivo se arrojan también víveres y medicina" ${ }^{43}$. En esta lógica nadie queda debidamente saciado. Gracias a la industria alimentaria motorizada, tendremos algún día más alimento que nunca, aunque quizá no nos alcance ya para poder comprarlo. En la aceleración y el incremento de esta dinámica, tal vez algún día no nos falte ya ni el pan ni la buena sopa, aunque posiblemente sí las ganas de comer, ya que aun quien tiene la suerte de tener algo que echarse en el estómago está expuesto al peligro de una indigencia mucho más profunda y radical.

El peligro de la hambruna, por ejemplo, y de los años de escasez, visto desde la totalidad y lo propio del destino occidental, no consiste de ninguna manera en que quizá muchos hombres perezcan, sino en que aquellos que sobrevivan sólo vivan aún para comer a fin de vivir. ${ }^{44}$

se encuentra de esta manera desacreditado". Sobre la tecnificación de la escritura cf. también Heidegger, M., GA 54, \$5; y Campbell, T., Improper life. Technology and Biopolitics from Heidegger to Agamben, Minneapolis, University of Minnesota Press, 2011, especialmente pp. 1-82.

42 Sobre la explosión de esta bomba atómica ontológica cf. la descripción de la jarra en M. Heidegger, "Das Ding", GA 7, pp. 165-187.

43 Esposito, R., Bios. Biopolítica y filosofía, trad. C. Molinari, Buenos Aires, Amorrortu, 2006, pp. 10-11. Cf. también Heidegger, Martin, GA 79, p. 27: "A través de tal disponer, la tierra deviene una cuenca carbonífera, el suelo un yacimiento mineral. Este disponer es ya de otro tipo que aquel a través del cual el campesino anteriormente disponía de su campo. El hacer campesino no provoca el suelo del campo; sino que más bien entrega la semilla a las fuerzas del crecimiento; las resguarda en su florecer. Sin embargo, entre tanto también el trabajo en el campo pasó al mismo dis-poner [Be-stellen] que hace [stellt] del aire nitrógeno, del suelo carbón y mineral, del mineral uranio, del uranio energía atómica, de ésta destrucción disponible. La agricultura es ahora industria alimentaria motorizada, en esencia lo mismo que la fabricación de cadáveres en las cámaras de gas y los campos de exterminio, lo mismo que el bloqueo y la producción de hambre en países, lo mismo que la fabricación de bombas de hidrógeno." Nótese la paradoja de que "la industria alimentaria motorizada, [sea] en esencia [...] lo mismo que el bloqueo y la producción de hambre”.

${ }^{44}$ Heidegger, M., GA 73.1, p. 880. Cf. Lévinas, E., De la existencia al existente, trad. P. Peñalver, Madrid, Arena Libros, 2000, p. 48: "Ciertamente no vivimos para comer, pero no es exacto decir que comemos para vivir. Comemos porque tenemos hambre. El deseo carece de segundas intenciones semejantes a pensamientos. Es buena voluntad. Todo lo demás es biología. Lo deseable es término, lo deseable es fin”. Sobre el hambre en Lévinas y 
La aceleración de la lógica productivista hace de la alimentación apenas un acto orgánico, fisiológico, el solo sostenimiento técnico de las funciones vitales, pero no ya de la vida. Frente al cuerpo sin órganos de Artaud, quedarían ahora los órganos objetivados -el Körper-, desarraigados del ser-en-el-mundo, y ya sin ningún cuerpo viviente $[\text { Leib }]^{45}$. Frente al hambre orgánica y fisiológica, hay otra hambre ontológicamente anterior que remite a la finitud del Dasein y no puede nunca ser saciada, puesto que remite a un modo original de apertura del mundo ${ }^{46}$.

Vivir significa entonces alimentarse, pero alimentarse bien, significativamente, y no la simple continuidad de las funciones orgánicas, capaz de ser extendida indefinidamente por la tecnociencia. Para recuperar el cuerpo viviente es necesario entonces recuperar correlativamente el alimento en su dimensión auténticamente existenciaria. El que se alimenta no es tanto, o no es sólo, el cuerpo físico [Körper] como el cuerpo viviente $[$ Leib]. No es el cuerpo el que tiene hambre, sino que soy en cada caso yo mismo, en mi íntegro ser-en-el-mundo el que siente que "le duelen las tripas” y reclama así un alimento que además de sostener su fisiología le da sentido al comer mismo.

su crítica a Heidegger cf. Ale, María S., De la responsabilidad por el otro hombre a la responsabilidad por el mundo en la obra de Emmanuel Levinas, Córdoba, Universidad Nacional de Córdoba, 2016.

45 Deleuze, G. y Guattari, F., “¿Cómo hacerse un cuerpo sin órganos?”, Mil mesetas, trad. J. Vázquez Pérez y U. Larraceleta, Valencia, Pre-Texos, 2004, pp. 155-171.

${ }^{46}$ Como sostiene J. M. Garrido: "Hambre es la experiencia original y singular de estar cortado de cualquier fuente de nutrición y de ser entregado a las propias manos en la impostergable tarea de no dejar de ser". Garrido, J. M., On Time, Being and Hunger. Challenging the Traditional Way of Thinking Life Nueva York, Fordham University Press, 2012, p. 41. En este punto diferimos de la interpretación de Escudero, quien señala que "El énfasis heideggeriano puesto en el presente como un modo de ser anclado en el conformismo y preso de las obligaciones cotidianas no sólo pasa por alto las necesidades corporales básicas del comer, dormir y beber, sino que también pasa por alto las relaciones cara a cara, la relación madre-nińo, los impulsos sexuales. Al centrarse exclusivamente en el trato instrumental del mundo del trabajo e ignorar los aspectos del dolor, la alegría y la tristeza del presente, resulta difícil explicar el origen de los deseos, la sexualidad y las emociones". Escudero, J. A., "Heidegger y el olvido del cuerpo", op. cit., p. 194. Sería necesario detenerse en cada uno de los aspectos que Heidegger ignoraría según Escudero, para demostrar que ello no es así. En este sentido, al ejemplo de las lágrimas en las que se manifiesta la tristeza y el alimento en su doble condición fisiológica y existenciaria, habría que agregar que tampoco los impulsos sexuales encarnarían meras necesidades fisiológicas de un cuerpo físico, sino que, por el contrario, serían la corporalización de una necesidad que en cada caso arraiga en el ser-en-el-mundo, eso que -sin ánimo alguno de banalizarlo con una definición- suele denominarse, tal vez, por ejemplo, "amor". De la misma manera, el dolor cotidiano, aun el físico, remitiría también al íntegro ser-en-el-mundo ya que, recordemos: "Un «desajuste» estomacal puede tender un velo de sombra sobre todas las cosas. Lo que en otro caso nos parece indiferente, es repentinamente irritante y molesto. Lo que en otro caso transcurre fácilmente, se paraliza." Heidegger, M., GA 6.1, p. 99. Una referencia similar acerca del dolor de estómago, en línea con el análisis de la enfermedad, puede encontrarse en GA 38, p. 153: “¿Qué es una enfermedad? Enfermedad no es la alteración de un proceso biológico, sino un suceder [Geschehen] histórico del hombre, algo que entre otras cosas se funda en un estar templado [Gestimmtsein]". En lo referente a la alegría cf. Heidegger, M., GA 9, p. 110: "Este aburrimiento hace manifiesto al ente en su totalidad.

Otra posibilidad de tal manifestación se esconde en la alegría ante la presencia del Dasein -no la mera personade un ser querido". 
El ser-en-el-mundo está en cada caso corporalizado. Pero del mismo modo en que la mundanidad del mundo carece de fundamento último, también lo hace el comer. De la muerte de los grandes valores y la imposición del nihilismo surge entonces la pregunta límite: ¿Para qué comer? ¿Por qué "hay que comer"? ¿Qué sentido puede tener este mandato en la época de la tecnociencia? ¿Para qué comemos? ¿Y para qué nos procuramos el alimento, día tras día? ¿De qué nos alimentamos? ${ }^{47}$ Pero si el cuerpo del Dasein no es sola ni principalmente un cuerpo biológico, si la vida que lo determina no equivale a la mera satisfacción de procesos fisiológicos, tampoco entonces la muerte puede ser comprendida en sentido ontológicamente propio como su simple detención. Los órganos cesan en su capacidad de encarnar el ser-en-el-mundo, sólo la mismidad, en cambio, vive y muere propiamente ${ }^{48}$.

\footnotetext{
${ }^{47}$ Me refiero a Derrida, J. y Nancy, J.-L., "Il faut bien manger" en AA.VV, Cahiers Confrontation, $\mathrm{N}^{\circ}$ 20, "Après le sujet qui vient”, París, Aubier, 1989, pp. 91-114. Una profunda indagación en esta cuestión puede verse en la película "El caballo de Turín" (2009) del director húngaro Béla Tarr, así también como en la que bien puede ser vista como su contrapartida: "La gran comilona" (1973), de Marco Ferreri. En efecto, mientras que la primera responde a la ausencia de sentido último con la suspensión del acto de comer, los personajes de la segunda prefieren, en cambio, comer hasta reventar. En ambos casos se trata, no obstante, de dos respuestas ante un mismo fenómeno: la pérdida de sentido del comer.

48 Cf. Heidegger, M., GA 2, \$49.
} 


\section{Referencias Bibliográficas}

Agamben, G., Homo Sacer I. El poder soberano y la nuda vida, trad. A. G. Cuspinera, Valencia, Pre-Textos, 2006.

Ale, María S., De la responsabilidad por el otro hombre a la responsabilidad por el mundo en la obra de Emmanuel Levinas, Córdoba, Universidad Nacional de Córdoba, 2016 [versión digital disponible en http://www.ffyh.unc.edu.ar/editorial/ wp-content/uploads/2013/05/EBOOK_ALE.pdf ]

Askay, R. R., "Heidegger, the body and the french philosophers", Continental Philosophy Review, N³2, Holanda, Kluwer, 1999, pp. 29-35.

Campbell, T., Improper life. Technology and Biopolitics from Heidegger to Agamben, Minneapolis, University of Minnesota Press, 2011. DOI: https://doi. org/10.5749/minnesota/9780816674640.001.0001

Deleuze, G. y Guattari, F., “CCómo hacerse un cuerpo sin órganos?”, Mil mesetas, trad. J. Vázquez Pérez y U. Larraceleta, Valencia, Pre-Texos, 2004.

Derrida, J., "La main de Heidegger”, Psyché. Inventions de l'autre, París, Galilée, 1987 , p. 438.

Derrida, J. y Nancy, J.-L., "Il faut bien manger", AA.VV, Cahiers Confrontation, $\mathrm{N}^{\circ}$ 20, “Après le sujet qui vient", París, Aubier, 1989, pp. 91-114.

Escudero, J. A., "Heidegger y el olvido del cuerpo", Lectora, N 17, pp. 181198, DOI: $10.2436 / 20.8020 .01 .30$.

Esposito, R., Bios. Biopolitica y filosofía, trad. C. Molinari, Buenos Aires, Amorrortu, 2006.

Esposito, R. y Goldenberg, M., "Violento estado de excepción”, Revista Eñe [en línea], 9 de noviembre de 2011, disponible en URL: http://www.revistaenie. clarin.com/ideas/Entrevista_Roberto_Esposito_0_493150696.html [revisado el 28 de enero de 2017].

Garrido, J. M., On Time, Being and Hunger. Challenging the Traditional Way of Thinking Life, Nueva York, Fordham University Press, 2012. DOI: https://doi. org/10.5749/minnesota/9780816674640.001.0001

HaAr, M. (comp.), Cahier de l'Herne consacré à Heidegger, París, L'Herne, 1983.

- Le chant de la terre. Heidegger et les assises de l'histoire de l'être, París, L'Herne, 1985. 
Haraway, D., Ciencia, cyborgs y mujeres. La reinvención de la naturaleza, trad. M. Talens, Madrid, Cátedra, 1995.

Heidegger, M., Ser y tiempo, trad. Jorge Eduardo Rivera C., Santiago de Chile, Editorial Universitaria, 1997.

- Sein und Zeit [GA 2], Frankfurt am Main, Klostermann, 1977.

- Nietzsche [GA 6.1], Frankfurt am Main, Klostermann, 1996.

- Vorträge und Aufsätze [GA 7], Frankfurt am Main, Klostermann, 2000.

- Was heisst Denken? [GA 8], Frankfurt am Main, Klostermann, 2002.

- Wegmarken [GA 9], Frankfurt am Main, Klostermann, 1976.

- Metaphysische Anfangsgründe der Logik im Ausgang von Leibniz [GA 26], Frankfurt am Main, Klostermann, 1978.

- Parmenides [GA 54], Frankfurt am Main, Klostermann, 1982.

- Zum Ereignis-Denken [GA 73.1], Frankfurt am Main, Klostermann, 2013.

- Bremer und Freiburger Vorträge [GA 79], Frankfurt am Main, Klostermann, 1994.

— Zollikoner Seminare [GA 89], Frankfurt am Main, Klostermann, 1987.

Husserl, E., Ideas II, trad. A. Zirión Q., México, FCE, 2005.

Inwood, M., A Heidegger dictionary, Oxford, Blackwell, 1999. DOI: https:// doi.org/10.5749/minnesota/9780816674640.001.0001

Jünger, Ernst, El trabajador, trad. A. Sánchez Pascual, Barcelona, Tusquets, 1993.

Kantorowicz, E., Los dos cuerpos del rey: un estudio de teología política medieval, trad. S. Aikin Araluce y R. Blázquez Godoy, Madrid, Akal, 2012.

Kundera, M., "Le geste brutal du peintre: sur Francis Bacon", Une rencontre, París, Gallimard, 2009.

LÉvinas, E., Totalité et infini. Essaie sur l'extériorité, París, Kluwer, 2000.

- De la existencia al existente, trad. P. Peñalver, Madrid, Arena Libros, 2000.

Merleau-Ponty, M., Phénoménologie de la perception, París, Gallimard, 1945.

Perruchot, H., Vida de Cézanne, trad. H. A. Maniglia, Buenos Aires, Hactette, 1955. 
Rodríguez SuÁrez, L. P., "Heidegger y el fenómeno del cuerpo. Apuntes para una antropología postmetafísica", Thémata. Revista de filosofía, N 46, 2012 (segundo semestre), pp. 209-216.

WARHOL, A., "What is pop art? Interviews with eight painters (Part 1)", AA.VV, Art news, Noviembre, Nueva York, 1963.

Zimmerman, M. E., Eclipse of the self, Ohio, Ohio University Press, 1986.

DOI: http://dx.doi.org/10.15366/bp2018.18.004

Bajo Palabra. II Época. No18. Pgs: 77-98 